\title{
MENANAMKAN SIKAP BERSAHAJA PADA ANAK USIA DINI DENGAN PEMBIASAAN MENABUNG
}

\author{
Ghina Maslihah Muharrom', Gina Nursyayidah Mukaromah², \\ Hendi Agus Dian ${ }^{3}$, Neng Syifa Ulfiah ${ }^{4}$,Elfan Fanhas Fatwa Khomaeny ${ }^{5}$ \\ ${ }^{1-5}$ Universitas Muhammadiyah Tasikmalaya \\ Email : ghinamaslihah12@gmail.com ${ }^{1}$,gnursyayidah@gmail.com², \\ hendiagusdian@gmail.com ${ }^{3}$, syifaulfiah98@gmail.com ${ }^{4}, \underline{\text { elfan.fanhas@umtas.ac.id }}$
}

\begin{abstract}
ABSTRAK
Pendidikan membangun karakter merupakan proses panjang yang harus dimulai sejak masa kelahiran anak walaupun baru dirasakan dampaknya setelah anak-anak tersebut tumbuh dewasa. Pendidikan karakter sejak dini merupakan pondasi awal dalam membentuk karakter di masa mendatang. Sikap bersahaja harus ditanamkan pada anak mulai sejak dini karena untuk memilah dan memilih antara apa yang dibutuhkan dan tidak dibutuhkan. Hidup bersahaja banyak memberi manfaat bagi kehidupan karena dapat memperteguh hati untuk selalu bersyukur atas apa yang Allah berikan dan hidup akan lebih berarti bagi sesama. Salah satu membiasakan anak usia dini bersahaja yaitu dengan cara menabung. Menabung berarti menyisihkan sebagian uang yang dimiliki untuk disimpan dalam jangka waktu tertentu. tujuan orang-orang dalam menabung pada umumnya sangatlah berbeda-beda tapi intinya adalah untuk memenuhi ekspektasi atau harapan di masa depan. Dengan menggunakan metode kualitatif, maka penelitian yang berupa kata-kata dan gambar dalam pengumpulan data-data, data tersebut mengandung makna yakni makna yang sebenarnya atau suatu nilai yang baik. Menanamkan sikap bersahaja pada anak usia dini dengan cara pembiasaan menabung.
\end{abstract}

Kata Kunci : anak usia dini, sikap bersahaja, pembiasaan menabung

\begin{abstract}
Character building education is a long process that must be started from childbirth even when it is felt after the children grow up. Early character education is an early foundation for character building in the future. Simple attitudes should be instilled in children starting early because to sort and choose between what is needed and not needed. Simple life provides many benefits for life because it can strengthen the heart to always be grateful for what God gives and life will be more meaningful to others. One of the habitual early childhood that is by way of saving. Saving means setting aside some of the money held for a certain period of time. the purpose of the people in saving in general is very different but the point is to meet expectations or expectations in the future. By using qualitative methods, the research in the form of words and images in the collection of data, the data contains the meaning of the true meaning or a good value. Embedding a simple attitude in early childhood by way of saving habituation.
\end{abstract}

Keywords: early childhood, modesty, saving habits 
Ghina Maslihah Muharromah, dkk. MENANAMKAN SIKAP BERSAHAJA PADA ANAK USIA DINI DENGAN PEMBIASAAN MENABUNG . Early Childhood Vol. 3 No. 1, Mei 2019

\section{PENDAHULUAN}

Masa usia dini merupakan masa usia emas (golden age) dalam menumbuh segala potensi yang ada pada diri anak. Sebagai pendidik, masa usia emas ini jangan dianggap remeh karena apapun yang didaptakan oleh anak akan direkam anak dalam pikirannya dan diimplementasikan anak dalam kehidupan sehari-harinya. Pendidikan anak usia dini pada dasarnya meliputi seluruh upaya dan tindakan yang dilakukan oleh pendidik dalam proses perawatan, pengasuhan dan pendidikan pada anak dengan menciptakan aura dan lingkungan. Dimana anak dapat mengeksplorasi pengalaman yang memberikan kesempatan kepadanya untuk mengetahui dan memahami pengalaman belajar yang diperolehnya dari lingkungan, melaui cara mengamati, meniru, bereksprimen yang berlangsung secara berulang-ulang dan melibatkan seluruh potensi dan kecerdasan anak.

Pendidikan membangun karakter akhlak mulia, dan moral merupakan proses panjang yang harus dimulai sejak masa kelahiran anak walaupun baru dirasakan dampaknya setelah anak-anak tersebut tumbuh dewasa. Pendidikan karakter sejak dini merupakan pondasi awal dalam membentuk karakter di masa mendatang. Menurut Widodo, dkk (Muchlas Samani dan Hariyanto, 2018 :
45) menyatakan bahwa pendidikan karakter sebagai aktifitas berbasis sekolah yang mengungkap secara sistematis bentuk perilaku siswa. Pendidikan karakter dihubungkan dengan sikap rencana sekolah yang dirancang bersama lembaga masyarakat yang lain untuk membentuk secara langsung dan sistematis perilaku orang muda. Hal ini berarti bahwa sekolah merupakan tempat yang strategis dalam membentuk karakter anak sehingga anak mempunyai akhlakul karimah atau kepribadian yang sehat. Tujuan pendidikan terkandung dalam setiap pengalaman belajar. Tujuan pendidikan sama dengan tujuan hidup manusia. Artinya pendidikan harus dilakukan agar mempunyai kehidupan yang baik dimasa mendatang. Menurut Hendro Widodo dan Avanti Vera Risti P (2018), masih banyak guru yang belum paham dan belum tahu, pendidikan karakter seperti apa yang diinginkan oleh pemerintah, mengingat setiap orang memiliki kecenderungan yang berbeda. Di samping itu, minimnya figur teladan dari para guru sesuai dengan kenyataan terhadap para pelajar.

Peraturan Menteri Pendidikan Nasional Nomor 16 Tahun 2007 kompetensi yang harus dimiliki guru adalah "menguasai karakteristik peserta didik pada aspek fisik, moral, sosial, kultural, emosional, dan intelektual". 
Ghina Maslihah Muharromah, dkk. MENANAMKAN SIKAP BERSAHAJA PADA ANAK USIA DINI DENGAN PEMBIASAAN MENABUNG . Early Childhood Vol. 3 No. 1, Mei 2019

(Depdiknas, 2007). Pendidik program PAUD memiliki kontribusi yang paling tinggi dalam menanamkan pendidikan karakter, akhlak mulia, dan moral setelah anak-anak membangun nilai moral dirumah melalui peran orangtua. Oleh sebab itu, apabila tidak diterapakan secara maksimal nilai- nilai karakter tersebut akan berakibat fatal untuk fase berikutnya, tetapi kalau diterapkan secara efektif akan membentuk karakter anak yang sopan santun.

Menurut Megawangi (Hendro Widodo dan Avanti Vera Risti P, 2018 :18) bahwa pendidikan karakter harus diberikan kepada anak sejak dini karena usia dini merupakan masa kritis pembentukan karakter seseorang. Kegagalan penanaman karakter pada seseorang sejak usia dini, akan membentuk pribadi yang bermasalah dimasa dewasa kelak. Dalam menanamkan karakter metode pendidikan yang metode ysang harus dikembangkan yaitu menempatkan anak sebagai pusat pendidikan, bukan pada kurikulum atau guru.

Anak yang cerdas dan yang baik adalah dua hal yang berbeda, masyarakat yang beradab sejak dahulu memiliki perhatian untuk pengembangan moral anak sebagai tujuan pendidikan sekolah. Tujuan pendidikan sekolah bukan sekedar untuk mengembangkan kemampuan kognitif, dan psikomotor, tetapi juga mengembangkan afektif untuk menjadi manusia yang baik, bahkan menjadi tujuan utama pendidikan.

Menurut KBBI (Kamus Besar Bahasa Indonesia) bersahaja artinya sederhana, tidak berlebihan. Artinya sikap yang tidak berlebihan atau merasa cukup terhadap apa yang telah dimilki. Sikap bersahaja harus ditanamkan pada anak mulai sejak dini karena untuk memilah dan memilih antara apa yang dibutuhkan dan tidak dibutuhkan.

Menurut Syatriadi (Ari Maulana, dkk : 2018), menabung berarti menyisihkan sebagian uang yang dimiliki untuk disimpan dalam jangka waktu tertentu. Tujuan orang-orang dalam menabung pada umumnya sangatlah berbeda-beda tapi intinya adalah untuk memenuhi ekspektasi atau harapan di masa depan. Sehingga bagi orang tua tak salah mengajarkan anaknya untuk menabung sejak usia dini. Tentunya mengajarkan menabung pada anak mempunyai tingkat kesulitan tersendiri yang dihadapi oleh para orang tua. Tapi dengan mengenalkan manfaat dari menabung kepada anak sejak ia telah menerima uang saku akan memudahkannya untuk mengetahui dampak positif dari menabung. Dan mengajari anak untuk gemar menabung haruslah berkelanjutan setiap harinya bahkan saat sang anak telah remaja atau 
Ghina Maslihah Muharromah, dkk. MENANAMKAN SIKAP BERSAHAJA PADA ANAK USIA DINI DENGAN PEMBIASAAN MENABUNG . Early Childhood Vol. 3 No. 1, Mei 2019

bahkan telah dewasa tetap penting terus mengajarinya untuk bisa menyisihkan sebagian dari uang sakunya untuk ditabung.

Manfaat menabung yang bisa dirasakan oleh anak yang telah terbiasa menyisihkan sebagian dari uang sakunya adalah sangat banyak sekali dan utamanya sang anak dapat berpikir dan bertindak menjadi lebih bijaksana dalam memilah-milah kebutuhannya dengan bimbingan orang tuanya. Para anak yang ingin menabung mempunyai tujuan yang sangat menginginkan sesuatu dengan uang sakunya sendiri. Sehingga dengan hadirnya orang tua disisinya akan membimbingnya untuk membelanjakan uang tabungannya ke hal-hal yang mendatangkan manfaat. Dengan menabung kita bisa menjadi pribadi yang lebih hemat dan tentu juga kita dapat belajar mengatur keuangan. Menurut Olvista (Ari Maulana, dkk : 2018), tujuan Menabung Membiasakan diri hidup hemat. Hidup hemat berarti tidak boros. Pengeluaran disesuaikan dengan kebutuhan dan memenuhi kebutuhan dalam jumlah besar dikemudian hari (Maulana, 2015). Selain itu, mengajarkan menabung sejak usia dini memili manfaat yaitu anak terbiasa belajar mengelola uang pribadi, memiliki perencanaan keuangan, menghargai uang, belajar disiplin, dan membuat kebanggaan.

\section{METODE PENELITIAN}

Metode penelitian yang akan digunakan dalam karya tulis ini ialah metode deskriptif, yaitu menggambarkan suatu kenyataan yang ada dilapangan saat dilakukannya sebuah penelitian. Menurut Nawawi (Nurul Yuliasari, M.Thamrin, Muhamad Ali. 2018 : 4) metode deskriptif adalah prosedur pemecahan masalah yang diselidiki dengan menggambarkan atau melukiskan keadaan subyek atau obyek penelitian pada saat sekarang berdasarkan faktafakta yang tampak atau sebagaimana adanya.

Dengan metode dan pendekatan tersebut, penelitian ini berfokus pada pelaksanaan penelitian di lapangan, dimana menurut Lincoln dan Guba (Arif Billah 2018 : 250) mengatakan "Pelaksanaan penelitian di lapangan secara garis besarnya terdiri dari tiga tahap, yaitu: tahap orientasi, eksplorasi, dan member check".

\section{HASIL DAN PEMBAHASAN}

\section{A. Menabung}

\section{Pengertian Tabungan}

Menurut Ari Maulana dan Jamalul Ail (2015:54) Menabung berarti menyisihkan sebagian uang yang dimiliki untuk disimpan dalam jangka waktu tertentu. 
Ghina Maslihah Muharromah, dkk. MENANAMKAN SIKAP BERSAHAJA PADA ANAK USIA DINI DENGAN PEMBIASAAN MENABUNG . Early Childhood Vol. 3 No. 1, Mei 2019

Tabungan adalah pendapatan yang diperloeh kemudian disimpan dalam jangka waktu tertentu untuk keperluan jika sewaktu-waktu dibutuhkan. Sedangkan menabung adalah perilaku seseorang dalam menyisihkan sebagian uang yang dimilikinya untuk disimpan untuk candangan masa yang akan datang.

\section{Tujuan Menabung}

Menurut Indra (1999:32) bahwa tujuan menabung adalah penyisihan sebagian hasil pendapatan yang diperoleh untuk dikumpulkan sebagai cadangan hari depan/masa depan dan sebagai alat untuk melakukan transaksi bisnis atau usaha individu / kelompok.

Menurut Maulana (Ari Maulana dan Jamalul Ail. 2015:54) Tujuan Menabung Membiasakan diri hidup hemat. Hidup hemat berarti tidak boros. Pengeluaran disesuaikan dengan kebutuhan dan memenuhi kebutuhan dalam jumlah besar dikemudian hari. Selain itu, mengajarkan menabung sejak usia dini memili manfaat yaitu anak terbiasa belajar mengelola uang pribadi, memiliki perencanaan keuangan, menghargai uang, belajar disiplin, dan membuat kebanggaan.

\section{Macam-Macam Tabungan}

Menurut Malayu. 2011:51 menyatakan bahwa macam-macam tabungan secara umum didapatkan dari beberapa sumber, diantaranya :

a. Sumber Tabungan Dalam Negeri

Jumlah tabungan yang tersedia di suatu negara secara sederhana merupakan hasil akumulasi atas jumlah tabungan domestik dan tabungan luar negeri.

b. Tabungan Domestik

Keseluruhan pengeluaran pemerintah dalam bentuk uang plus semua aliran modal keluar (capital outflows) untuk pembelian peralatan-peralatan militer.

c. Tabungan Pemerintah

Tabungan pemerintah merupakan kelebihan pendapatan pemerintah dari sektor pajak dan sumber- sumber lainnya, setelah pendapatan ini digunakan untuk pengeluaran rutin.

\section{B. Pendidikan Karakter}

Menurut Mulyasa (2016 : 3) pendidikan karakter memiliki makna lebih tinggi dari pendidikan moral, karena pendidikan karakter tidak hanya berkaitan dengan masalah benar-salah, tetapi bagaimana menanamkan kebiasaan (habit) tentang hal-hal yang baik dalam kehidupan, sehingga anak/peserta didik memiliki kesadaran, dan pemahaman yang tinggi, serta kepedulian dan komitmen untuk menerapkan kebajikan dalam kehidupan sehari-hari. Dengan demikia dapat dikatakan bahwa karakter merupakan sifat alami seseorang dalam 
Ghina Maslihah Muharromah, dkk. MENANAMKAN SIKAP BERSAHAJA PADA ANAK USIA DINI DENGAN PEMBIASAAN MENABUNG . Early Childhood Vol. 3 No. 1, Mei 2019

merespons situasi secara bermoral, yang diwujudkan dalam tindakan nyata melalui perilaku baik, jujur, bertanggung jawab, hormat terhadap orang lain, dan nilai-nilai karakter mulia lainnya. Dalam konteks pemikiran islam, karakter berkaitan dengan iman dan ikhsan.

Wyne (1991) [Mulyasa (2016 : 3)] mengemukakan bahwa karakter berasal dari bahasa Yunani yang berarti "to mark" (menandai) dan memfokuskan pada bagaimana menerapkan nilai-nilai kebaikan dalam tindakan nyata atau perilaku sehari-hari. Oleh sebab itu, seseorang yang berperilaku tidak jujur, curang, kejam, dan rakus dikatakan sebagai orang yang memiliki karakter jelek, sedangkan yang berperilaku baik, jujur, dan suka menolong dikatakan sebagai orang yang memiliki karakter baik/mulia.

Menurut Mulyasa (2016 : 5) Megawangi, pencetus pendidikan karakter di Indonesiatelah menyususn 9 pilar karakter mulia yang selayaknya dijadikan acuan dalam pendidikan karakter, baik di sekolah maupun luar sekolah, yaitu sebagai berikut :

1. Cinta Alah dan kebenaran

2. Tanggung jawab, disiplin, dan mandiri

3. Amanah

4. Hormat dan santun

5. Kasih sayang, peduli, dan kerja sama
6. Percaya diri, kreatif, dan pantang menyerah

7. Adil dan berjiwa lepemimpinan

8. Baik dan rendah hati

9. Toleran dan cinta damai

Dalam perspektif Idlam, pendidikan karakter secara teoretik sebenarnya telah da sejak Islam diturunkan di dunia, seiring dengan diutusnya Nabi Muhammad saw. untuk memperbaiki atau menyempurnakan akhlak (karakter) manusia. Ajaran Islam sendiri mengandung sistematika ajaran yang tidak hanya menekankan pada aspek keimanan, ibadah dan mu'amalah, tetapi juga akhlak. Pengalaman ajaran Islam secara utuh (kaffah) merupakan model karakter seorang muslim, bahkan dipersonifikasikan dengan model karakter Nabi Muhammad saw., yang memiliki sifat Shidiq, Tabligh, Amanah, Fathonah (STAF).

Menurut Elfan Fanhas F. Kh. dan Gina Nurazizah Mukhlis (2017 : 46) penanaman karakter bukanlah sebuah proses yang instan, tetapi merupakan proses panjang yang dilakukan secara bertahap dan berkelanjutan, dimulai sejak anak dalam kandungan sampai anak mencapai dewasa (baligh). Pendidikan karakter untuk AUD dalam ajaran Islam tertuang dalam Al-Qur'an dan Hadits, diantaranya konsep pendidikan karakter Nabi Ibrahim, Nabi Yakub, Nabi Zakaria, 
Ghina Maslihah Muharromah, dkk. MENANAMKAN SIKAP BERSAHAJA PADA ANAK USIA DINI DENGAN PEMBIASAAN MENABUNG . Early Childhood Vol. 3 No. 1, Mei 2019

Nabi Daud, Nabi Muhammad, Lukmannul Hakim, dan para nabi lainnya. Konsep pendidikan karakter Lukmanul hakim menarik untuk dikaji karena beliau bukanlah nabi dan rasul, bagian dari masyarakat biasa secara strata sosial maupun ekonomi, dan ulasan konsep ajarannya dalam Al-Qur`an lebih terperinci, terstrukur, dan sistematis.

Konsep pendidikan karakter yang dipakai oleh Lukmanul Hakim dalam mendidik anaknya adalah konsep terbaik, karena referensi utamanya dari kitab suci yang diturunkan oleh sang Khalik yang maha mengetahui akan makhluknya. Orang tua muslim haruslah menguasai dan mengamalkan konsep pendidikan tersebut sehingga dapat menjalankan amanah dalam mendidik anak.

\section{Bersahaja}

Menurut Kamus Besar Bahasa Indonesia (KBBI) besahaja adalah sederhana, tidak berlebih-lebihan. Gaya hidup bersahaja dan sederhana merupakan salah satu gaya hidup yang dicontohkan oleh Rasulullah SAW. Rasulullah memilih gaya hidup sederhana dan berzuhud dengan dunia dan isinya. Inilah keteladanan gaya hidup yang ditunjukkan oleh pemimpin besar seperti Rasulullah. Rasulullah bukan lah orang yang tak bisa kaya raya. Hidup zuhud menjadi pilihan dirinya sebagai seorang Nabi dan Rasul.

Seorang Rasul adalah contoh tauladan bagi ummatnya, maka apa yang dipilih oleh Rasulullah adalah suru tauladan terbaik yang akan membuat hidup lebih bahagia. Meskipun gaya hidup bersahaja dan sederhana merupakan gaya hidup yang dipilih oleh Rasulullah, namun beliau tidak pernah melarang ummatnya untuk menjadi kaya. Bahkan beliau mendukung ummat Islam untuk menjadi kaya.Para sahabat di masa Rasulullah seperti Usman bin Affan merupakan sahabat dari kalangan yang kaya raya yang selalu siap menafkahkan kekayaannya untuk dakwah Islam. Islam meminta ummatnya untuk menjadi kaya agar dari kekayaan itu diberikan untuk kemaslahatan dakwah Islam itu sendiri.

Penanaman sikap bersahaja pada Anak Usia Dini (AUD) tidak sekedar memberi pengetahuannya saja tetapi lebih pada menumbuhkan kesadaran dan menerapkannya dalam kehidupan seharihari. Oleh karena itu harus dilakukan secara lembut dan menyenangkan. Suasana dan lingkungan yang aman dan nyaman, perlu diciptakan dalam proses penanaman nilai-nilai sikap bersahaja itu sendiri. Untuk memperdalam pemahaman sikap bersahaja yang diharapkan, setiap nilai sikap tersebut yang telah dimasukan 
Ghina Maslihah Muharromah, dkk. MENANAMKAN SIKAP BERSAHAJA PADA ANAK USIA DINI DENGAN PEMBIASAAN MENABUNG . Early Childhood Vol. 3 No. 1, Mei 2019

ke dalam rencana pembelajaran harus diterapkan secara berkelanjutan.

Menurut Direktorat Jenderal PAUD Dan Pendidikan Masyarakat Direktorat Pembinaan PAUD (2015 : 24) ada 5 langkah yang perlu diperhatikan dalam menanamkan sikap pada anak:

1. Anak dikenalkan dengan perilaku dan nilai yang baik dan seharusnya (knowing the good)

2. Anak diajak membahas untuk memikirkan dan mengerti mengapa ini baik dan itu tidak baik (thinking the good)

3. Anak diajak merasakan manfaat bila perilaku baik itu diterapkan (feeling the good)

4. Anak diajak melakukan perilaku yang baik ( acting the good)

5. Anak dibiasakan untuk menerapkan sikap baik dalam setiap kesempatan (habituating the good).

\section{SIMPULAN}

Penanaman sikap bersahaja pada Anak Usia Dini (AUD) tidak sekedar memberi pengetahuannya saja tetapi lebih pada menumbuhkan kesadaran dan menerapkannya dalam kehidupan seharihari. Oleh karena itu harus dilakukan secara lembut dan menyenangkan. Suasana dan lingkungan yang aman dan nyaman, perlu diciptakan dalam proses penanaman nilai-nilai sikap bersahaja itu sendiri. Untuk memperdalam pemahaman sikap bersahaja yang diharapkan, setiap nilai sikap tersebut yang telah dimasukan ke dalam rencana pembelajaran harus diterapkan secara berkelanjutan. Salah satu usaha menanmakan sikap bersahaja pada Anak Usia Dini adalah dengan kegiatan menabung.

\section{DAFTAR PUSTAKA}

Billah, Arif. (2016) Pendidikan Karakter untuk Anak Usia Dini dalam Perspektif Islam dan Implementasinya dalam Materi Sains. Journal of Islamic Culture and Education.

Depdiknas. Kompetensi Guru (2007). Indonesia.

Elfan Fanhas F Kh, Gina Nurazizah Mukhlis. Pendidikan Karaktek Untuk Anak Usia Dini Menurut Q.S. Lukman : 13-19. PEDAGOGI: Jurnal Anak Usia Dini dan Pendidikan Anak Usia Dini Volume 3 Nomor 3a Desember 2017 Hal. 42-51

Lincoln, Y. S. \& Guba, E. G. (1985). Naturalistic Inquiry. Beverly Hills, Calif: Sage Publications

Lickona, T. (1992). Educating for Character, How Our Schools Can Teach Respect and Responsibility. New York: Bantam Books.

Muhaimin. (2012). Paradigma Pendidikan Islam. Bandung : PT Remaja Rosdakarya.

Nurul Yuliasari, M.Thamrin, Muhamad Ali. Pembiasaan perilaku tertib 
Ghina Maslihah Muharromah, dkk. MENANAMKAN SIKAP BERSAHAJA PADA ANAK USIA DINI DENGAN PEMBIASAAN MENABUNG . Early Childhood Vol. 3 No. 1, Mei 2019

pada anak usia 5-6 Tahun di Taman Kanak-kanak Ananda Pontianak Barat. FKIP UNTAN.

Nawawi, Hidari. (2007). Metode Penelitian Bidang Sosial. Yogyakarta : Gadjahmada University Press.

Soelaeman. (1985). Suatu Upaya Pendekatan Fenomenologis Terhadap Situasi Kehidupan dan Pendidikan dalam Keluarga dan Sekolah. Disertasi Doktor Pascasarjana. Bandung: FPS IKIP Bandung

Widodo, Hendro dan Vera, Avanti. (2017). Pendidikan Karakter Holistik Integratif di PAUD Terpadu Aisyi'ah NurAini Ngampilan Yogyakarta. Jurnal Pendidikan Anak. 

Ghina Maslihah Muharromah, dkk. MENANAMKAN SIKAP BERSAHAJA PADA ANAK USIA DINI DENGAN PEMBIASAAN MENABUNG . Early Childhood Vol. 3 No. 1, Mei 2019

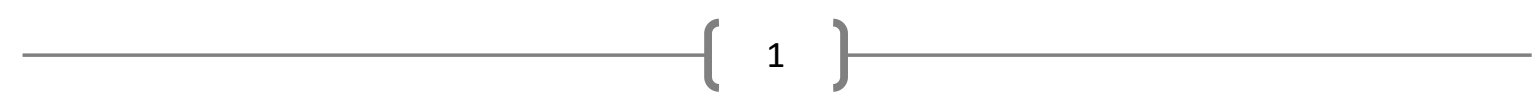

